\title{
Forecasting the Inflation Rate in Nigeria: Box Jenkins Approach
}

\author{
J.T Olajide ${ }^{1}$, O.A. Ayansola ${ }^{1}$, M.T. Odusina ${ }^{2}$, I.F. Oyenuga ${ }^{1}$ \\ ${ }^{I}$ Department of Mathematics \& Statistics, the Polytechnic, Ibadan, Oyo State, Nigeria \\ ${ }^{2}$ Department of Mathematics \& Statistics, the Polytechnic, Ibadan, Adeseun Ogundoyin Campus, Eruwa, Oyo \\ State, Nigeria
}

\begin{abstract}
This paper aims to forecast the inflation rate in Nigeria using Jenkins approach. The data used for this paper was yearly data collected for a period of 1961-2010. Differencing method were used to obtain stationary process. The empirical study reveals that the most adequate model for the inflation rate is ARIMA $(1,1,1)$. The model developed was used to forecast the year 2011 inflation rate as $16.27 \%$. Based on this result, we recommend effective fiscal policies aimed at monitoring Nigeria's inflationary trend to avoid the consequences in the economy.
\end{abstract}

Key words: ARIMA models, Box-Jenkins, Differencing method, forecasting, Inflation rate.

\section{Introduction}

In economics the inflation rate is a measure of inflation, or the rate of increase of a price index such as consumer price index. It is the percentage rate of change in price level over time [1]. The maintenance of price stability is one of the macroeconomic challenges facing the Nigeria government in our economic history [2]. In an inflationary economy, it is difficult for the national currency to act as medium of exchange and a store of value without having an adverse effect on the income distribution [ 3 ]. Inflation is characterized by a fall in the value of the country's currency and rise in her exchange rate with other nation's currencies. This is quite obvious in the case of the value of naira(\#), which was \#1 to \$1 (US dollar) in 1980's, average of \#100 to \$1 in year 2000 , \#128 to $\$ 1$ in 2003 and over \#155 to $\$ 1$ in 2011 [4]. This decline in the value of the Naira coincides with the period of inflationary growth in Nigeria. Increased exchange rate directly affects the prices of imported commodities and an increase in the price of imported goods and services contributes directly to inflation [2].

There are three approaches to measure inflation. They are the Gross National Product(GNP), the consumer price index(CPI) and the wholesome or producer price index (WPI and PPI). The period to period changes in these two latter approaches (CPI and WPI) are regarded as direct measure of inflation.

Forecasting inflation can be done using time series analysis, relevant literature was scarce. Literature on modeling and forecasting tourism demand in various type of empirical analysis [5]. Some of the researchers apply cross-sectional data, but most of forecasting tourism demand used pure time-series modeling, which was specified based on the famous standard Box-Jenkins method. Many researchers has applied this methodology see for example [6], [ 5], [7], [4] etc.

Studies which focus on forecasting inflation rate in Nigeria have appeared in various research publications. [4] examined whether monetary aggregates have useful information for forecasting inflation in the case of Nigeria other than that provided by inflation itself using a sample data spanning from 1990 to 1998 . The study adopted two approaches, mean absolute percentage Errors (MAPE's) and autoregressive model. The study revealed that the treasury bill rate, domestic debt and M2 (broad money) provide the most important information about price movements.

[8 ] take a much more simple approach to determining future inflation. In their paper, they acknowledge inflation to be a relatively persistent process, which implies that future inflation rates are greatly affected by past current rates. After determining this, they felt it necessary to include any other economic variables in their analysis. Their paper compares the accuracy of the predictive model. The first are in a simple regression with a sample of 40 quarters. The second is what they refer to as the naive model, which was created by Atkesm and Ohanian in 2001. In it, they simply state that the forecasted inflation for the next year in the four quarter growth rate in CPI in the present year. they concluded both models were capable of performing each other depending on time period.

[9] article makes the simple prediction that even though gas and food prices are rising, which will lead to a higher CPI, inflation stay relatively constant because consumer expectations will remain constant.

[10] provides a similar predictive for both Canada and US inflation rates, however with different methodology .he says both rates should remain fairly steady despite the continued rise in gas and food prices.

[6] use autoregressive integrated moving average(ARIMA) model to predict inflation in Ghana using monthly inflation figures. In building the ARIMA model they use Box-Jenkinis approach, this inflation was found to integrated of order one and follows $(6,1,6)$ order. 
Motivated by these research, this paper intends to predict inflation rate in Nigeria through ARIMA approach. Also, the following specific objectives will be pursued: to build an appropriate Autoregressive Integrated Moving Average (ARIMA) model for inflation in Nigeria and forecast the inflation rate in Nigeria.

\section{Methodology}

The data used for this study consists of annual data on Nigeria- inflation, consumer prices (annual percent) for the period of 1961 to 2010 extracted from the official website of World Bank data base.

In this study we use ARIMA model to forecast one-period ahead of the series by applying Box-Jenkins approach. An ARIMA model is a generalization of an ARMA model. The model is generally referred to as ARIMA ( $, d, q$ ) model where $p, d$ and $q$ are integers greater than or equal to zero and refer to the order of the autoregressive, integrated and moving average aspects.

The Box-ARMA model is a combination of the AR(Autoregressive) and MA(Moving Average) models as follows:

$$
y_{t}=\beta_{0}+\beta_{1} y_{t-1}+\ldots+\beta_{p} y_{t-p}-\alpha_{1} u_{t-1}-\alpha_{2} u_{t-2}-\ldots-\alpha_{q} u_{t-q}+u_{t}
$$

The Box-Jenkins methodology [11], [12] is a five-step process for identifying, selecting, and assessing conditional mean models (for discrete, univariate time series data). The steps are listed below:

1. Establish the stationarity of your time series. If your series is not stationary, successively difference your series to attain stationarity. The sample autocorrelation function (ACF) and partial autocorrelation function (PACF) of stationary series decay exponentially (or cut off completely after a few lags).

2. Identify a (stationary) conditional mean model for your data. The sample ACF and PACF functions can help with this selection. For an autoregressive (AR) process, the sample ACF decays gradually, but the sample PACF cuts off after a few lags. Conversely, for a moving average (MA) process, the sample ACF cuts off after a few lags, but the sample PACF decays gradually. If both the ACF and PACF decay gradually, consider an ARMA model.

3. Specify the model, and estimate the model parameters. When fitting non-stationary models in Econometrics Toolbox, it is not necessary to manually difference your data and fit a stationary model. Instead, use your data on the original scale, and create an arima model object with the desired degree of non-seasonal and seasonal differencing. Fitting an ARIMA model directly is advantageous for forecasting: forecasts are returned on the original scale (not differenced).

4. Conduct goodness-of-fit checks to ensure the model describes your data adequately. Residuals should be uncorrelated, homoscedastic, and normally distributed with constant mean and variance. If the residuals are not normally distributed, you can change your innovation distribution to a Student's $t$.

5. After choosing a model and checking its fit and forecasting ability, you can use the model to forecast or generate Monte Carlo simulations over a future time horizon.

\section{Analysis And Result}

We obtain the CPI data in Nigeria from 1961 to 2010. The plot of the CPI showed that the time series data was non stationary. But the plot of the differences of the CPI, as shown in fig. 1 showed considerable volatility even though the first differences are stationary. In order to determine whether the data was stationary we conducted an Augmented Dickey Fuller test (fig. 2) with the null hypothesis that the process contains unit roots. The test returned a p-value of approximately 0.00 and the null was rejected at $5 \%$ significance level. We continued our analysis with the assumption of stationarity. Since the data was confirmed stationary, it was observed that it was better to use the first difference of the series, so as to build a good model. In other words, the series was an integration of the first order. The autocorrelation function (ACF) and the partial autocorrelation function (PACF) graphs of the first difference confirm the results of the unit root test as discussed earlier (fig. 1).

The next step was to estimate the model, in this regard, a test was carried out on $\operatorname{AR}(1)$ and $\operatorname{AR}(2)$ as

shown in table 1 with the Akaike Information Criteria (AIC) of 8.029 and 7.96 respectively.

\begin{tabular}{|l|l|l|l|l|l|}
\hline Model & Coefficient & RMSE & AIC & Mean dependent variable & $R^{2}$ \\
\hline $\begin{array}{l}\text { AR(1) } \\
\text { AR(1) }\end{array}$ & 17.2499 & & & & \\
\hline MA(1) & 0.6291 & 13.14 & 8.029 & 16.99 & 0.398 \\
\hline MA(1) & 16.7989 & & & & \\
\hline ARIMA(1,1,1) & 0.7216 & 12.67 & 7.96 & 16.77 & 0.43 \\
\hline AR(1) & 17.069 & & & & \\
MA(1) & 0.3158 & 12.55 & 7.95 & 16.99 & 0.46 \\
\hline
\end{tabular}


In carrying out the test for ARIMA process, ARMA $(1,0,1)$ was derived and an AIC value of 7.95. However, since the series are integrated of order one as per the result of unit root test our model can be stated as ARIMA $(1,1,1)$.

The tentative models that were identified for the set of time series data are $\mathrm{AR}(1), \operatorname{MA}(1)$ and $\operatorname{ARMA}(1,1)$. Considering the tentative models (as shown in table 1) revealed that the best model is $\operatorname{ARIMA}(1$, $1,1)$ since it has the smallest root mean square (RMSE) of 12.55, least Akaike Information Criteria (AIC) of 7.95and the highest coefficient of determination of 0.46 which implies that the model is $46 \%$ fit.

Diagnostic checking: one simple diagnostic is to obtain the residuals, say, up to lag 25 . The BoxPierce $G$ and Ljung-Box (LB) statistic (Q-statistic) in fig 3 shows that non of the ACF and PACF are statistically significant. In other words, the correlogram of both autocorrelation and partial autocorrelation give the impression that the residuals estimated from ARIMA model $(1,1,1)$ are purely random. Hence, there may not be any need to look for another ARIMA model.

Therefore, the estimator of ARIMA $(1,1,1)$ model is validated, the time series can be described by an ARIMA $(1,1,1)$ process. The inflation rate seasonal adjusted time series and in first-differences (DCPI) is described as:

$$
D C P I=17.069+0.3158 y_{t-1}+0.5653 u_{t-1}
$$

The forecast is done using a statistical package e (E-view), the residual value for the data was also obtained and used to predict the inflation rate for 2011 to be $16.27 \%$ using ARIMA $(1,1,1)$.

Date: 09/13/12 Time: 10:23

Sample: 1961- 2010

Included observations: 49

\begin{tabular}{|c|c|c|c|c|c|c|}
\hline Autocorrelation & Partial Correlation & & $\mathrm{AC}$ & PAC & Q-Stat & Prob \\
\hline.$||$. &.$||$. & 1 & 0.014 & 0.014 & 0.0095 & 0.922 \\
\hline ****. & ****1. & 2 & -0.403 & -0.404 & 8.6646 & 0.013 \\
\hline .*1. & $*$ & 3 & -0.104 & -0.109 & 9.2527 & 0.026 \\
\hline.$* 1$. & $* * \mid$. & 4 & -0.076 & -0.289 & 9.5716 & 0.048 \\
\hline. & $*$ & 5 & 0.028 & -0.096 & 9.6172 & 0.087 \\
\hline . $*$. & .1. & 6 & 0.186 & 0.018 & 11.632 & 0.071 \\
\hline. & .1. & 7 & 0.063 & 0.017 & 11.864 & 0.105 \\
\hline.$* 1$. & $*$. & 8 & -0.158 & -0.098 & 13.378 & 0.099 \\
\hline.$* 1$. & .1 & 9 & -0.081 & -0.037 & 13.788 & 0.130 \\
\hline .1 &. & 10 & 0.053 & -0.011 & 13.966 & 0.175 \\
\hline$*$ & $*$. & 11 & -0.080 & -0.174 & 14.385 & 0.212 \\
\hline .1 & .1 & 12 & 0.020 & -0.049 & 14.413 & 0.275 \\
\hline . ${ }^{*}$. &.$* 1$. & 13 & 0.092 & -0.069 & 14.995 & 0.308 \\
\hline & .1. & 14 & 0.050 & 0.056 & 15.171 & 0.367 \\
\hline * & * & 15 & -0.145 & -0.181 & 16.723 & 0.336 \\
\hline.$* 1$. &.$* 1$. & 16 & -0.134 & -0.156 & 18.080 & 0.319 \\
\hline.$\left.\right|^{*}$. & . $\left.\right|^{*}$. & 17 & 0.179 & 0.080 & 20.582 & 0.246 \\
\hline .1 & $*$ & 18 & 0.062 & -0.073 & 20.894 & 0.285 \\
\hline .1. & .1. & 19 & 0.019 & 0.060 & 20.923 & 0.341 \\
\hline.$j$. &.$j$. & 20 & 0.069 & 0.053 & 21.339 & 0.377 \\
\hline
\end{tabular}

fig .1 The correlogram of first difference of inflation rate in Nigeria.

Null Hypothesis: D(CPI) has a unit root

Exogenous: Constant

Lag Length: 1 (Automatic - based on SIC, maxlag=10)

\begin{tabular}{lccc}
\hline \hline & t-Statistic & Prob.* \\
\hline \hline Augmented Dickey-Fuller test statistic & -7.181206 & 0.0000 \\
\hline Test critical values: & 1\% level & -3.577723 & \\
& 5\% level & -2.925169 & \\
& 10\% level & -2.600658 & \\
\hline \hline
\end{tabular}

*MacKinnon (1996) one-sided p-values.

Augmented Dickey-Fuller Test Equation

Dependent Variable: D(CPI,2)

Method: Least Squares 
Date: 09/17/12 Time: 09:07

Sample (adjusted): 19642010

Included observations: 47 after adjustments

\begin{tabular}{lrlrl}
\hline \hline \multicolumn{1}{c}{ Variable } & Coefficient & Std. Error & t-Statistic & Prob. \\
\hline \hline \multicolumn{1}{c}{ D(CPI(-1)) } & -1.385779 & 0.192973 & -7.181206 & 0.0000 \\
D(CPI(-1),2) & 0.403840 & 0.137382 & 2.939536 & 0.0052 \\
\multicolumn{1}{c}{0.392279} & 2.002205 & 0.195923 & 0.8456 \\
\hline \hline R-squared & 0.578147 & Mean dependent var & 0.215745 \\
Adjusted R-squared & 0.558971 & S.D. dependent var & 20.66776 \\
S.E. of regression & 13.72546 & Akaike info criterion & 8.138083 \\
Sum squared resid & 8289.079 & Schwarz criterion & 8.256178 \\
Log likelihood & -188.2450 & Hannan-Quinn criter. & 8.182523 \\
F-statistic & 30.15081 & Durbin-Watson stat & 2.079621 \\
Prob(F-statistic) & 0.000000 & & \\
\hline \hline
\end{tabular}

fig. 2 Augmented Dickey fuller test

Date: 09/17/12 Time: 11:06

Sample: 19622010

Included observations: 49

Q-statistic

probabilities adjusted

for 2 ARMA term(s)

\begin{tabular}{|c|c|c|c|c|c|c|}
\hline Autocorrelation & Partial Correlation & & $\mathrm{AC}$ & PAC & Q-Stat & Prob \\
\hline .1. & .1. & 1 & -0.014 & -0.014 & 0.0098 & \\
\hline .1. & .1. & 2 & -0.001 & -0.001 & 0.0098 & \\
\hline .1. & .1. & 3 & 0.052 & 0.052 & 0.1550 & 0.694 \\
\hline .1. & .1. & 4 & 0.009 & 0.011 & 0.1599 & 0.923 \\
\hline .1. & .1. & 5 & 0.058 & 0.059 & 0.3517 & 0.950 \\
\hline.$\left.\right|^{*}$. &.$\left.\right|^{*}$ & 6 & 0.141 & 0.141 & 1.5123 & 0.824 \\
\hline .1. & .1. & 7 & 0.043 & 0.048 & 1.6198 & 0.899 \\
\hline$* \mid$. &.$* 1$. & 8 & -0.084 & -0.090 & 2.0540 & 0.915 \\
\hline$*$. & *. & 9 & -0.093 & -0.116 & 2.5957 & 0.920 \\
\hline .1. & .1. & 10 & 0.058 & 0.042 & 2.8078 & 0.946 \\
\hline$* 1$. & $*$. & 11 & -0.138 & -0.151 & 4.0678 & 0.907 \\
\hline .1. & .1. & 12 & 0.020 & -0.001 & 4.0946 & 0.943 \\
\hline .1. & .1. & 13 & -0.022 & -0.027 & 4.1267 & 0.966 \\
\hline .1. &.$\left.\right|^{*}$. & 14 & 0.019 & 0.074 & 4.1524 & 0.981 \\
\hline$* 1$. & * & 15 & -0.097 & -0.066 & 4.8400 & 0.979 \\
\hline$* 1$. & $* 1$. & 16 & -0.128 & -0.131 & 6.0780 & 0.964 \\
\hline.$\left.\right|^{*}$. &.$\left.\right|^{*}$. & 17 & 0.143 & 0.168 & 7.6736 & 0.936 \\
\hline .1. & .1. & 18 & 0.011 & 0.039 & 7.6840 & 0.958 \\
\hline. $\mid$ & .1. & 19 & -0.036 & -0.043 & 7.7939 & 0.971 \\
\hline.$\left.\right|^{*}$. & .1. & 20 & 0.109 & 0.073 & 8.8113 & 0.964 \\
\hline
\end{tabular}

fig. 3. Correlogram of residual 
$\mathrm{CPI}$

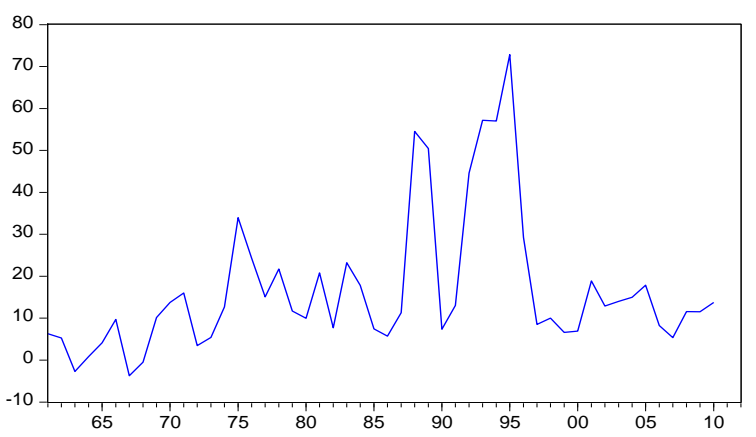

Fig. 4 graph of annual inflation rate during the period of 1961-2010

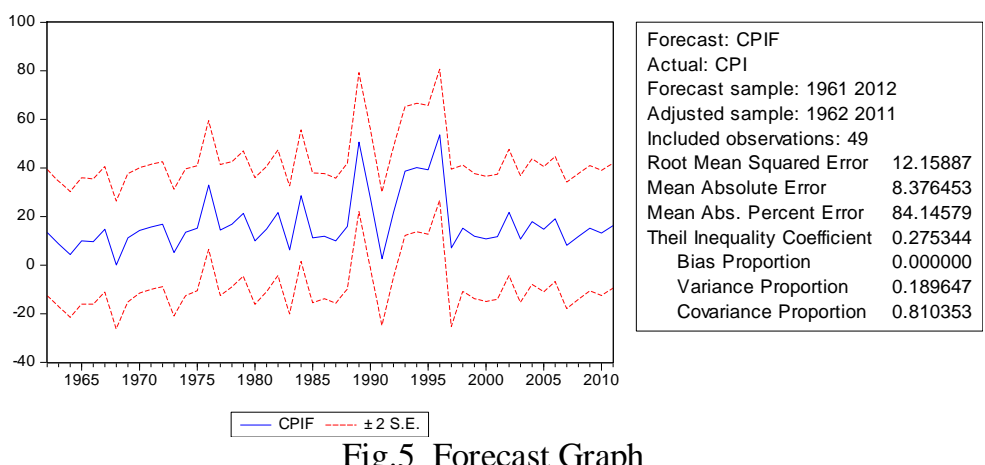

\section{Conclusion}

This study aimed at predicting inflation rate in Nigeria using ARIMA model. The time series data is not stationary at level. By applying the ADF test for the series of the first order differences we observed that the series becomes stationary, so the initial series of the annual inflation rate is integrated by first order. We then applied the Box-Jenkins procedure on the stationary data series and we identify the corresponding ARIMA ( $p$, q) process. The series correlogram has allowed us to choose appropriate $\mathrm{p}$ and $\mathrm{q}$ for the data series. Therefore, units root test was conducted and the null of the series integrated of order one was not rejected. We finally, built an ARIMA $(1,1,1)$ model.

The root mean square error (RMSE) which determine the efficiency of the model was estimated at 12.55, this indicate that the model built is efficient. Using an ARIMA $(1,1,1)$ model of annual value series of inflation rate for 2011 is estimated to be $16.27 \%$.

\section{References}

[1] S. Arthra and S.M. Sheffarin, Economic: Principle in action (Upper Saddle River, New Jersey, Pearson Prentice Hall, 2003 pp:340)

[2] Bayo Fatukasi, Determinants of inflation in Nigeria: An Empirical Analysis, International Journal of Humanities and Social Science 1(18).

[3] Central Bank of Nigeria " "Money supply, inflation and the Nigerian economy" ,Bullion Publication of CBN, 21 (3), 1996.

[4] P. I. Nwosa et al, Monetary policy, exchange rate and inflation rate in Nigeria, research Journal on Finance and Accounting (3) (3), 2012.

[5] C. K. Lee, H. J. Song \& J. W. Mjelde, The forecasting of international expo tourism using quantitative and qualitative techniques, Tourism Management, 29(6), 1084-1098, 2008

[6] S. E. Alna and F. Ahiakpor, ARIMA (autoregressive integrated moving average) approach to predicting inflation in Ghana. Journal of Economics and International Finance 3(5), pp. 328-336, May 2011

[7] K.. Wong, H. Song, S. F. Witt \& D. C. Wu , Tourism forecasting: to combine or not to combine? Tourism Management, 28, 10681078,2007

[8] Meyer, B. H.Meyer \& M. Pasaogullari, "Simple Ways to Forecast Inflation: What Works Best?" Federal Reserve Bank of Cleveland: Economic Commentary. Retrieved from http://www.clevelandfed.org/research/commentary/2010/2010-17.cfm, 2010 June

[9] D. Wessel, "Tinker Bell Economics Colors Inflation Predictions." The Wall Street Journal. Retrieved from http://online.wsj.com/article/ SB10001424052748704520504576162322026133298.html, 2011. February

[10] A. Carrick, "January Inflation Remained under Control in Both Canada and US" Reed Construction Data Retrieved from http://www.reedconstructiondata.com/contruction -forecast/news/2012/02/january-inflation-remand-under-control-in both-theUSand-Canada/, 2012

[11] G. E. P.Box, G. M. Jenkins, and G. C. Reinsel, Time Series Analysis: Forecasting and Control. (Upper Saddle River, NJ: Prentice-Hall $3^{\text {rd }}$ edition, 1994).

[12] D.N . Gujarati and D.C. Porter, Basic Econometrics (McGraw-Hill Companies Inc, $5^{\text {th }}$ edition, New York, USA, 2009) 